\title{
Fragmentos de ética: figuraçōes do historiador oitocentista em Alexandre Herculano
}

Fragments of ethics: figurations of the nineteenth-century historian in Alexandre Herculano

\section{Evandro Santos}

\section{RESUMO}

Este artigo parte da análise de textos do jornalista, escritor e historiador português oitocentista Alexandre Herculano (1810-1877), ainda pouco explorados pelos estudos de História da historiografia brasileiros. Majoritariamente produzidos entre 1841 e 1850, eles retratam o âmbito de discussões acerca do processo de reformas liberais portuguesas. Ao examinar os embates de Herculano com os clérigos de Lisboa no que se refere à educação pública e às crenças religiosas por ele revistas em suas obras históricas, o objetivo geral deste texto é verificar a construção da figuração propriamente historiográfica do discurso produzido pelos historiadores, tanto por meio de suas práticas de crítica e instrumentos de verificação, quanto, sobretudo, pela atuação pública daqueles que se dedicavam ao estudo do passado. A experiência de leitura de tais documentos aponta para importantes questões que dizem respeito ao processo de historicização do papel do historiador como crítico da sociedade, o que viria a ser concebido depois como uma função central do intelectual.

\section{PALAVRAS-CHAVE}

História da historiografia; Ética para os historiadores; Alexandre Herculano.

\section{ABSTRACT}

This paper analyzes texts written by the nineteenthcentury journalist, writer and historian Alexandre Herculano (1810-1877) that have been little explored in Brazilian studies of history of historiography. Mostly produced between 1841 and 1850, the texts present discussions about the process of Portuguese liberal reforms. By examining the confrontations between Herculano and the clergymen from Lisbon concerning public education and religious beliefs approached by him in his historical works, the general objective of this paper is to verify the construction of the historiographical figuration of the discourse produced by historians in their practices of criticism and instruments of verification, and particularly through the public action of those who were dedicated to study the past. The experience of reading such documents has pointed out important issues regarding the process of historicization of the historian's role as a critic of society, something that would later be conceived as the central function of an intellectual.

\section{KEYWORDS}

History of historiography; Ethics for historians; Alexandre Herculano. 
Cabe notar também que essa ética do civismo em torno da História é contemporânea, ainda, do desenvolvimento da ética revolucionária militante na historiografia contraposta a uma ética da neutralidade cientifica. Em grande medida, estas vertentes demarcam, ainda hoje, o debate sobre o papel do conhecimento histórico. A divisāo coloca também sob interrogaçāo as formas de participaçāo do profissional de História na esfera pública, entre o distanciamento e o engajamento. (KNAUSS 2008, p. 144).

\section{Sobre o historiador...}

Uma das mais conhecidas polêmicas em que se envolveu o importante letrado português Alexandre Herculano (1810-1877) diz respeito às concepções apresentadas pelo historiador sobre dois mitos de base religiosa em sua História de Portugal, a partir de 1846. Na verdade, a reformulação do universo social e literário, necessidade por ele concebida no contexto posterior à chamada regeneração portuguesa que adveio dos movimentos liberais dos anos 1820 e 1830, inevitavelmente entrava em confronto com determinadas definições da cultura portuguesa de sua época (PROENÇA 1987). A moral católica defendida por Herculano entrara em choque com sua noção de crítica histórica e frente aos seus enfrentamentos políticos com o clero português (CARVALHO 1971). Mesmo antes da publicação de sua grande obra histórica, havia divulgado pela imprensa indicações de suas restrições quanto aos dogmas religiosos e à atuação da instituição católica, tanto em suas Cartas sobre a História de Portugal quanto em panfletos avulsos (HERCULANO 1841; 1842).

Neste artigo, alguns escritos menos conhecidos de Herculano serão trabalhados no intuito de discutir as características do debate historiográfico sobre a conduta do historiador na pesquisa e escrita da História no Portugal do século XIX. Cabe salientar a importância da obra do letrado português para a compreensão das figurações acerca do ofício do historiador em meados do Oitocentos, cujos destaques estão para além da historiografia, e residem também na produção periódica e na ficção no formato do romance, como era comum naquele momento (MARINHO 1999). Da mesma maneira, é factível a constatação de que avançar na leitura de Herculano pode auxiliar na exploração da produção histórica e literária dos letrados brasileiros de sua época. ${ }^{1}$

1. Este artigo é, em grande medida, inspirado reflexões de TURIN (2009) e OLIVEIRA (2010), que refletem sobre as figurações do historiador no caso brasileiro. 


\section{Herculano e a instruçāo pública}

Os textos avulsos de Herculano constituem preciosas fontes ao conhecimento de posicionamentos que estavam subsumidos em sua vasta obra. Nesse sentido, o interesse de Herculano pela religião é de fundamental importância no esforço de compreensão do impacto das reformas liberais em Portugal, mas, sobretudo, da visão sobre a instituição religiosa e seu forte passado de domínio no país, especialmente em função da Inquisição (SARAIVA 1949). O exercício de historicização da Igreja demarcava quase a plenitude dos escritos historiográficos de Herculano. Um entre inúmeros exemplos é o caso do texto "Conversão dos godos ao catholicismo" (HERCULANO s/d) no qual se tem que conhecer o passado da instituição era uma forma de realocá-la dentro do presente, no lugar devido. Esta era a concepção aparentemente expressa em Herculano. Demonstrar os conflitos que envolveram a conversão dos godos hispanoromanos ao catolicismo era uma forma de retirar o caráter místico desse decurso, eliminando "certa índole maravilhosa" (HERCULANO s/d, p. 3). Conforme o historiador,

os escritores coetâneos, que nos conservaram a memória do grande fato da substituição do catolicismo ao arianismo como religião do estado, eram católicos, e, por isso, interessados em revestir esse acontecimento de circunstâncias maravilhosas, e a espontaneidade da conversão da nobreza gótica e do clero ariano não era das menos importantes. Devem, por isso, aproveitar-se as suas narrativas com a mais circunspecta crítica (HERCULANO s/d, p. 4-5). ${ }^{2}$

A postura crítica de Herculano impedia qualquer leitura no sentido de considerar as disputas religiosas algo espontâneo. ${ }^{3}$ O domínio do discurso religioso, assim como a espontaneidade transmitida nas narrativas religiosas, não poderia ser aceito, inclusive pelos vestígios deixados nas narrativas e monumentos históricos, apesar do controle religioso (HERCULANO s/d, p. 22). Nesse sentido, as conclusões do letrado eram as seguintes:

nos domínios da revelação a inteligência humana abstém-se, porque ao racionalmente impossível se apoia o indubitável. Nos

2. A ortografia demarcada nas fontes foi atualizada em todas as citações deste artigo.

3. Importa referir
as reflexões
do FOUCAULT
(2010) acerca das
possibilidades da
análise de discursos
comorecurso
teórico à história da
historiografia.


domínios da razão o milagre, que é o impossível, separou-se do indubitável, e a razão forçadamente o rejeita como ádvena e peregrino. Aquém das fronteiras da revelação não há milagres: há ignorância ou mentira (HERCULANO s/d, p. 30).

Havia, sem dúvida, neste gênero de crítica, o duplo propósito de reafirmar práticas da pesquisa histórica e ingressar no debate sobre o papel da Igreja na nova sociedade que se organizava. Esse emblema político das divulgações de Herculano encaminharia sua atenção, desde cedo, para o tema da educação em seu país. Neste aspecto, embora a História, entendida como disciplina, tenha sido convertida em matéria voltada à formação básica dos jovens membros das elites, nem sempre se observara nas figurações do historiador seu vínculo e sua participação ativa no debate sobre a educação, em sentido mais amplo. Para além do prisma mais filosófico ou semântico da historia magistra vitae, a História, para os envolvidos com tal assunto no século XIX, auxiliava na reestruturação das sociedades na modernidade. Dito de outra forma, a pesquisa histórica atribuía legitimidade às reformas e colaborava com a correção dos equívocos percebidos nas permanências do passado.

Em outro artigo, intitulado justamente Instrucção publica, editado originalmente no Diário do Governo, em 1838, Herculano comentava os problemas na instituição da educação primária em Portugal, afirmando que a educação superior existia, mas seria complementar em uma nação; e que a educação primária, mais importante, ainda não existia. Os esforços para a instituição desse nível de ensino datam de 1833, conforme o autor: "a porta por onde se entra no santuário da Ciência é a boa educação primária" (HERCULANO s/d, p. 34).

Leitor de Guizot, Thierry e Cousin, o letrado não deixaria de esboçar os paralelos possíveis entre as diversas nações europeias:

o filósofo Cousin, mandado à Prússia pelo governo francês para examinar o estado do ensino público naquele país, à sua volta declarou, no relatório que fez, que a França estava ainda 
atrasadíssima neste ramo. E acaso a França é inferior à Prússia em sábios e em literatos? Não, por certo; mas sem dúvida o é nas instituições de ensino primário. Assim, entre os dois povos há uma grande diferença de instrução popular, e, por consequência, de moralidade (HERCULANO s/d, p. 34-35).

O peso lançado sobre a importância da educação básica e a sua relação com os avanços de qualquer sociedade são constantemente retomados em diversos momentos por Herculano. O seu conhecimento de idiomas diversos e a experiência da viagem alimentaram muitas das suas visões formuladas quando de seus tempos em Coimbra. A partir de sua avaliação, resulta "que os povos da Alemanha são os mais bem morigerados de todos, porque a ilustração é o verdadeiro fundamento da moral" (HERCULANO s/d, p. 35). Observa-se aqui a tópica do letrado viajante, que compreende por comparação. De certa maneira, tal caráter mais geral seria incorporado à figura do historiador oitocentista, o que corresponde, entretanto, à retomada de um valor colocado desde a Antiguidade, em nomes consagrados como Heródoto e Tucídides. O saber, produzido e transmitido, catalisa-se através do contato com realidades diversas. Trata-se de um aspecto antropológico, mas também ético e político, que pode ser pensado em suas especificidades para recortes particulares.

Nesse sentido, é pertinente observar que o dilema antigo da educação moral permanece, mas os modelos retóricos do ensino devem ser abandonados aos olhos de Herculano, uma vez que

é esta uma obrigação social da infância e mocidade, como na virilidade o é pagar tributos, ser soldado, jurado, ou sofrer outro qualquer dos encargos públicos. Tal é a face por onde principalmente encaramos a instrução primária, posto que dela também resultem vantagens individuais. Mas é isto o que nós temos? De que serve ao comum dos homens o latim e o grego das Seletas, os tropos de Quintiliano, a Filosofia caquética de Genovesi ou de Heineck? - E que temos por essas aulas menores em todo o Portugal senão esta ferragem, de que, dez anos depois de a ter metido na cabeça, ninguém se lembra, salvo de traduzir gaguejando algum trecho de latim ou grego, 
traduzido e impresso em línguas vulgares de há muito tempo? - Será isto instrução popular? Estamos convencidos de que não (HERCULANO s/d, p. 41-42).

A convicção de que a ausência do ensino popular básico atrasava a sociedade portuguesa e a constatação de que tal retardo estava relacionado com uma visão ultrapassada da política educacional ficavam nítidas na fala do crítico:

dividimos em um artigo antecedente, a instrução inferior em duas classes - os preparatórios para estudos superiores e o ensino popular, ou antes, social. Este não existe em nosso país; aquele existe, mas sem satisfazer aos seus fins e às necessidades do século: mais como um monumento do passado, do que como uma instituição do presente (HERCULANO s/d, p. 43).

A nova sociedade que deveria emergir após as revoluções liberais necessariamente exigiria a reforma de métodos e matérias. Em diversos excertos da obra de Herculano, é possível verificar sua preocupação com a diversificação nos meios de transmissão dos conhecimentos. Conforme já havia indicado, por exemplo, em um tratado escrito anteriormente, a retórica e a poética compunham área de urgência na reforma. Na concepção de Herculano, ambas eram totalmente incapazes de contribuir à formação do cidadão moderno. Já não se tratava mais do grande orador do passado, mas sim de homens capazes de, coletivamente, representar a nação. Assim, retoma-se a importância da instrução pública básica. 0 recurso à memorização de máximas e lugares comuns já não dava conta da construção da eloquência, recurso ainda válido na esfera pública. A regeneração das leis e instituições, proposta no contexto de produção ora examinado, reivindicava a figura do agente político com oratória em potencial. Herculano não se furtaria, inclusive, de destacar suas referências primordiais: "aonde sejam mais conhecidos Cícero e Demóstenes do que Quintiliano e Barbosa (HERCULANO s/d, p. 47).

Herculano dedicou boa parte de seus estudos ao tema das reformas curriculares e manifestou-se politicamente, pela imprensa, em muitas oportunidades ao longo da segunda 
metade da década de 1830 (MACHADO 2011). De acordo com o crítico, a população jovem que tinha acesso às informações dos clássicos gregos e romanos não mais transformava tais técnicas em conhecimento útil à cidadania. A organização geral da sociedade, no que se referia à religião, à moral e aos saberes científicos, não era mais adequada ao espaço público português. ${ }^{4} \mathrm{~A}$ moderna concepção de História se fazia presente e, naquela ocasião, o passado era marcador de diferença. $\mathrm{O}$ conhecimento sobre o pretérito ocidental, portanto, situava o historiador em outro patamar, aquele que poderia atuar diretamente em um dos principais ministérios de qualquer nação moderna: a educação. Atuação pública que passou a atribuir à História legitimidade que o processo de disciplinarização, pouco a pouco, viria a abrir mão.

\section{A verdade histórica define o historiador}

De acordo com António Sérgio, Herculano saiu do Porto e foi a Lisboa dirigir o Panorama em 1837. Ficou lá por sete anos. Em 1839, é nomeado pelo rei consorte D. Fernando, diretor da Biblioteca da Ajuda, cargo que ocupa até 1867, quando se retira para Vale-de-Lobos. Em razão de sua visão na História de Portugal, o questionamento da visão religiosa da batalha de Ourique foi atacado pelo clero. ${ }^{5}$ Então, escreveu opúsculos (HERCULANO 1937, p. 10). Antes mesmo da publicação completa de sua grande obra histórica, por meio de cartas ao editor, impressas originalmente na Revista Universal Lisbonense, Herculano já comunicava o recebimento de críticas às suas análises e conclusões. Adiantava o autor:

a razão por que hei de abster-me de responder por enquanto aos que me combatem ou combaterem é porque, fazendo-o, satisfaria o meu amor próprio; não o fazendo cumpro o meu dever. Anunciei a publicação anual de um volume da História Portuguesa; é uma obrigação que contraí para com muitos centenares de maus cidadãos, como eu, que não se escandalizam da falta de patriotismo que reina no mal aventurado livro (HERCULANO 1846, p. 509). 
Na mesma carta, ao responder diretamente às críticas direcionadas à sua negativa relacionada ao mito do Milagre de Ourique, um dos marcos religiosos fortes da criação nacional portuguesa, Herculano demarca claramente sua distância em relação aos dogmas do catolicismo. À tal forma de argumentação atribui bases na tradição. Sua fé, diz ele, está sustentada em documentos. A tradição, convertida em prova pelo clero português, é oral. A própria natureza de tal registro é questionada pelo autor, quando esse se converte em historiador. $O$ pretérito transmitido pelos relatos orais não seria, em si, suficiente para resguardar o milagre que fundamentaria a monarquia portuguesa em seus inícios modernos. Os documentos de época seriam as fontes mais seguras para qualquer estudo histórico. A ideia de um passado diferente do presente e acessível apenas pelo registro coevo forçava, simultaneamente, a atribuição de novo lugar à verdade religiosa e ao próprio tempo histórico. Além disso, não satisfeito em diferenciar a História da tradição professada pela Igreja, Herculano destacava que o diálogo da tradição com a poesia poderia operar com o tradicional de forma superficial, o que não seria permitido à História. A poesia recebe, ainda, importância superior na resposta trazida pelo historiador. Para ele, exemplo maior de tal superioridade é, por exemplo, a supremacia de Camões para a cultura portuguesa. A História seria algo mais simples; e o historiador, mais humilde. O mérito da imaginação não poderia ser alimentado nessa ciência como era estimulado na poesia (HERCULANO 1846, p. 513).

Como se pode observar, a definição da verdade em História passou a ser discutida por Herculano imediatamente após as críticas à primeira publicação da História de Portugal. Especificamente sobre o caso de Ourique, chegou a discutir, ao fim da carta, suas análises e confrontos entre fontes documentais. Sua manifestação nessa primeira resposta aos comentadores de sua obra encaminhou-se, no fundamental, no sentido de reforçar o que já havia dito na advertência que abre o tomo de 1846. Sustentava certa imparcialidade que era garantida pela própria prática histórica. O afastamento do 
sujeito de conhecimento seria garantido pela nova concepção de verdade advinda de estudos sustentados e legitimados por documentos e por uma forma diversa de se examinar o passado nacional, enfoque do século XIX. O patriotismo, para Herculano, seria adequado, novamente, ao poeta, mas não ao historiador. No limite, tal motivação, quando dominante na escrita da História, garantiria descrédito tanto ao autor quando ao próprio país. É interessante observar que o investimento pessoal de Herculano em escrever uma grande História de Portugal não é colocada em questão, por ele mesmo, como um gesto submetido ao conceito de patriotismo aos poucos construído em sua época (HERCULANO 1846, p. VIII). De todo modo, o afastamento exigido entre o lugar de fala do historiador e seu objeto reforça modelos antigos de isenção metodológica que, no recorte oitocentista, operam com as temporalidades de maneira diversa. Não se trata de um passado eternizado, mas alocado em um sistema de sentido que o movimenta. A releitura de tais textos oferece, em grande medida, possibilidades ao repensar sobre os limites da autorreflexão desenvolvida pelos historiadores nas últimas quatro décadas, grosso modo. Uma das questões que se pode colocar diz respeito à permanência de vasta produção historiográfica que, a despeito da crítica que se efetuou à categoria nação, segue submetida a essa, sem qualquer indagação epistemológica mais consistente.

Entretanto, no que tange à polêmica de Ourique, seria apenas o começo de um longo debate que marcaria a carreira de Herculano e a historiografia do país em meados do Oitocentos. Em 1850, uma nova onda de protestos contra a sua interpretação envolveria respostas à imprensa e ao clero de Lisboa. Perseguir as respostas de Herculano permite vislumbrar o estado do debate acerca do conceito de História no Portugal da época e, em grande medida, situar os diálogos que o letrado construía com as instituições de seu tempo (MATOS 2008).

A primeira entrada possível é a missiva enviada por Herculano ao redator do periódico $A$ Nação, intitulada considerações pacíficas sobre o opúsculo Eu e o clero, datado 
de 25 de julho de 1850. O comprometimento moral demarcado nos resultados apresentados na História de Portugal foi, desde o início, levantado pelo autor do opúsculo, "[...] numa questão que me respeitava pessoalmente, e que até certo ponto estava comprometido, não só o meu caráter literário, mas também, o que mais é, o meu caráter moral" (HERCULANO 1850a, p. 4). Como um argumento a ser retomado com frequência nas polêmicas letradas oitocentistas, o historiador ressalta, desde o início, a busca por justiça, sendo essa uma das funções centrais da imprensa. Ao comentar o ataque que o jornal $A$ nação fez contra ele após a resposta de parte do clero a seus escritos, escreve Herculano: "é assim que o sacerdócio da imprensa cumpre a sua grave missão, e remedeia do modo possível a decadência do sacerdócio religioso" (HERCULANO 1850a, p. 4).

Sustentado por sua vasta investigação e pelo tempo dedicado à escrita da obra e formulação de suas conclusões, o historiador reafirmava sua posição crítica à atuação do clero em Portugal:

na minha vida literária tenho dado mais de um documento de que costumo ser sincero. Estou persuadido de que a maioria do nosso clero é tal como eu a qualifiquei, e se não fosse repugnância a despedaçar um cadáver, daria aqui as razões da minha persuasão. Em todo o caso, aceito inteira a responsabilidade dela: não tergiverso, não me arrependo. Tenho dito e escrito muitas verdades, senão mais deploráveis, por certo mais perigosas para mim, sem que o meu sono deixasse de ser profundo, como o é habitualmente (HERCULANO 1850a, p. 6).

Herculano faz questão de enfatizar que o respeito à ideia de santidade dos papas e eventos tratados pela tradição oral, como o aparecimento de Ourique, compõem a crença católica. ${ }^{6}$ A vinculação do adjetivo "sincero" à figura do historiador merece atenção. Trata-se do reforço de tópica comum aos letrados oitocentistas. A sinceridade seria garantia de autoridade, mas também um gesto quase profissional, um dever de ofício. O historiador seria, então, aquele que diz o que instituições longevas não gostariam de ouvir (e, muitas vezes, o que se privavam de falar), marcando, novamente, sua posição crítica.
6. A recente reflexão de François Hartog acerca da ideia de crença na História e de sua própria historicidade contribui à leitura aqui apresentada (HARTOG 2013). 
Nesse sentido, ele lembra, inclusive, que, no tocante aos milagres, desde a época medieval, os bispos estavam proibidos de falar ou divulgar qualquer informação sem a devida comprovação institucional: "ordenam aos mesmos oradores que não falem impudentemente de milagres, limitando-se aos que refere a Bíblia, ou aos que forem narrados por escritores de peso [...]" (HERCULANO 1850a, p. 10). Assim, o argumento de resposta encontrava força na própria postura da Igreja: ao longo de sua própria História, essa instituição religiosa tratou ciosamente de matéria tão pouco afeita à investigação histórica, na leitura de Herculano.

A partir de informações históricas ligadas à Igreja, Herculano reagia ao ataque do próprio clero da época. A valorização da informação verídica e a postura dos padres e bispos medievais são trazidas como argumento na defesa do historiador. O reconhecimento do valor da instituição religiosa não é negado. Pelas formulações do autor do opúsculo, podese observar tanto mais um conflito acerca da construção histórica do que uma tradição oral de pertinência política. As acusações de corrupção direcionadas aos papas do passado são reafirmadas pelo autor da História de Portugal como conclusões históricas, ao mesmo tempo em que afirma não bastar "ciência e literatura", estando a verdade acima da prática, como virtude maior, uma vez que:

É verdade que V. S. a cobre Hildebrando com a égide da canonização e Inocêncio III com o da sua ciência e literatura. Mas nem eu vejo que ciência e literatura sejam sinônimos de virtude, nem creio que uma canonização constitua dogma de fé, e obste à liberdade do historiador para avaliar como entender os caracteres históricos. V. S. ${ }^{\text {a }}$ sabe perfeitamente que, fundando-se as canonizações em provas humanas, e não em fatos revelados, as decisões pontifícias a tal respeito são falíveis, o que bem se manifesta da oração, que ainda no século XIV os papas faziam na solenidade das canonizações, pedindo a Deus permitisse que não se houvessem enganado. Esta doutrina é corrente, e V. S. a não a ignora, não poderia ignorá-la" (HERCULANO 1850a, p. 10). 
Herculano comenta que os escritores protestantes criticaram os pontífices em questão. A seguir, complementa dizendo que os historiadores protestantes modernos também criticaram outros papas. Faz apelo à comparação para fortalecer seu argumento. A pretensão que dominaria o papa Hildebrando poderia ser verificada nas fontes e na comparação com a grande figura contemporânea ao Oitocentos: "não há nessas ideias um orgulho, uma intolerância para com os poderes da terra, que não compreenderíamos, talvez, hoje, se não tivesse vivido no nosso século uma inteligência igualmente vasta e enérgica, chamada Napoleão Bonaparte?" (HERCULANO 1850a, p. 13). A síntese produzida por Herculano consistia em converter a crítica histórica em elemento moral, ao passo que seu ponto de vista reafirmava que a condenação às más práticas deveria satisfazer a todo e qualquer cristão. A correção do mal feito seria o caminho defendido, inclusive, pela Igreja.

Em sua resposta, Herculano diz ainda que São Tomaz de Aquino também criticou Inocêncio IV e outros. Aquino, segundo o historiador, teria sido o mais profundo filósofo do século XIII. Segue-se uma argumentação no sentido de que, se Aquino é considerado um doutor da igreja e fez as críticas devidas, ele teria o mesmo direito letrado de fazê-lo. A carta é encerrada com a reafirmação da abertura à correção da História de Portugal, contudo, dentro dos limites da crítica erudita e histórica: "gosto de ser advertido dos erros em que caio, quando é a ciência e o talento quem se incumbe deste mister, e certifico a V. S. a de que facilmente me retrataria, se nas suas ulteriores observações V. S. a me convencesse de que eu errava" (HERCULANO 1850a, p. 17).

Os enfrentamentos do historiador com o clero católico não cessaram e houve diversos desdobramentos. Suas reflexões sobre o tema, já registradas desde os textos das décadas de 1830 e 1840, o perseguiriam por toda a vida. Em sua correspondência, é possível mapear como, já retirado à região de Vale de Lobos, local que escolheu para viver depois de publicada sua obra maior, Herculano ainda respondia a 
indagações sobre suas concepções da instituição religiosa e seu domínio no espaço público português. A título de exemplo, é possível citar as cartas trocadas com A. B. Barros Gomes, num total de quatro missivas, nas quais o historiador reforça suas opiniões sobre o catolicismo (HERCULANO s/d, Tomo I, p. 9-29). Em julho de 1876, respondia ao seu interlocutor: "[...] admira-me a exaltação religiosa num homem de ciência, em quem, parece, os sentimentos desta ordem deveriam ser tranquilos e desassombrados. Deus não nos deu inutilmente a razão. A revelação completa-a, não a exclui. Esta é o degrau para chegarmos àquela" (HERCULANO s/d, p. 9). A carta supracitada é uma resposta às críticas de Barros Gomes à obra O pároco da aldeia, de autoria de Herculano. Ele comenta que escreveu esse livro aos 25 ou 26 anos, e que agora, aos 66, não percebia motivos para corrigi-la (HERCULANO s/d, p. 10). Entretanto, é importante observar que a pecha de crítico da fé católica atribuída por seus detratores não deve conduzir ao ponto de vista de um Herculano agnóstico ou mesmo ateu. A importância da religião para a ordem da sociedade era reafirmada em diversos de seus escritos. A crítica, função dos historiadores, e a reforma da sociedade apenas impunham um novo espaço à instituição e um olhar distanciado sobre ela. Uma carta a Casal Ribeiro, de 17 de dezembro de 1876, diz algo a esse respeito:

a indiferença pela dor alheia, sobretudo quando impotente e obscura, é o grande vício do século. O calor parece ir-se retirando deste músculo chamado o coração humano, à medida que o cristianismo se vai alongando das consciências. A caridade torna-se num produto que, semelhante a muitos produtos da nossa indústria, se fabrica expressa e exclusivamente para as exposições ruidosas. Varremos às vezes as grandes misérias, porque também varremos as ruas. $O$ asco incumbe-se não raro do papel da compaixão no teatro do mundo (HERCULANO s/d, Tomo II, p. 45). ${ }^{7}$

Ainda acerca do posicionamento historiográfico e político de Herculano no que se refere à leitura sobre os mitos religiosos, uma carta enviada a Salustiano Rodriguez Bermejo, em 9 de fevereiro de 1873, importa, por reforçar um dos desdobramentos

\section{Conforme lembra Maria Isabel Buescu, o retorno de Herculano ao tema da polêmica com o clero, em 1876, tem como pano de fundo a publicação de seus Opúsculos (BUESCU 2012, p. 126).}


do episódio polêmico ocorrido entre 1850 e 1851. Nessa carta, Herculano comenta duas de suas obras mais conhecidas, uma da mocidade, outra da idade em que passava a romper com o mundo das letras: Eurico e Historia da Inquisição. Bermejo propunha verter para o espanhol a obra sobre o tribunal católico. Do primeiro, limita-se a tecer comentários estéticos, dizendo que é dos trabalhos entre os quais mais percebe erros. Sobre o segundo, contudo, afirma que fora escrita com clara intenção política, o que está registrado na advertência preliminar que abre a obra. O historiador efetua leitura crítica da obra, esclarecendo que a parte inicial do texto até o reinado de $D$. Manuel é propositalmente superficial, pois não era seu objetivo principal examinar o passado inquisitorial português, mas o período mais recente. No entanto, a finalidade política que motivou o estudo e a reflexão presentes no trabalho em nada compromete, na opinião de Herculano, o cuidado que dedicou à investigação. Ele é rígido na avaliação que faz da atuação e comemora o fato de haver documentos que comprovam a atuação da inquisição, algo tão cruel que poderia ser desacreditado não fossem os registros escritos. Destaca a importância da preservação impressa desses materiais pelo Corpo Diplomático português e pela Academia de Lisboa (HERCULANO s/d, Tomo II, p. 144-145). ${ }^{9}$

Contanto, uma das fontes privilegiadas ao exame historiográfico da polêmica revisitada ao longo deste artigo é, sem dúvida, o opúsculo Solemnia verba, de 1850, ano da querela (HERCULANO 1850b). O documento constitui-se de duas cartas escritas por Herculano e direcionadas a A. L. Magessi Tavares, a primeira em 20 de outubro e a segunda em 6 de novembro do referido ano. Inicialmente, o historiador apresenta sua discordância com relação à crença no mito de Ourique, sem perder oportunidade de dizer que o mito religioso de fundação da nação portuguesa em nada comprometia sua devoção nacional. "Peço a V. S. a e aos ânimos honestos, que pensam como V. S. a, se persuadam de que o homem que não admite certas narrativas infundadas, nem por isso deixa de ser bom português; e que se não está excessivamente inclinado a

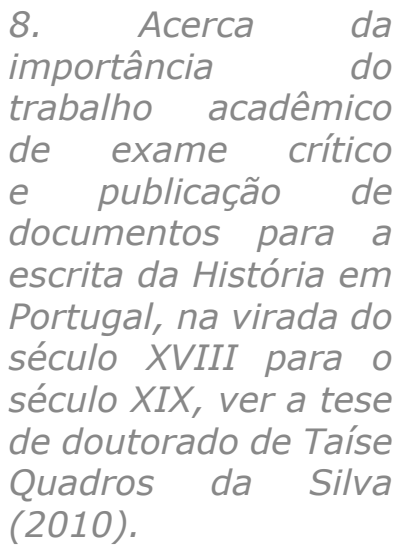
(2010). 
adorar o Deus de Ourique, nem por isso deixa de crer em Deus" (HERCULANO 1850b, p. 5). Ademais, importa acompanhar a passagem a partir da qual Herculano avançava sobre o sentido historiográfico de seu trabalho. O historiador reafirmava que para concordar com suas apreciações acerca dos dogmas católicos sobre a participação da instituição religiosa na fundação da História portuguesa "era necessário ter convindo em certo número de princípios, aceitar certas fórmulas de raciocínio". Herculano criava um dissenso entre a leitura do religioso e a sua própria avaliação. Além disso, ampliava essa divergência, ao situar sua atuação histórica no âmbito dos "homens de ciência" e da "razão comum". Ao mesmo tempo, situava a História como conhecimento privilegiado na Europa de seu tempo, saber que, à época, teria avançado como poucos (HERCULANO 1850b, p. 6-8).

Herculano menciona a importância do desenvolvimento da diplomática como fundamento técnico e metodológico no exercício da pesquisa com documentos antigos. A diplomática, entendida como ciência dos arquivos, teria preservado, mas, sobretudo, revelado o valor dos registros escritos preservados sobre o presente e o passado português. Tal exame dos arquivos seria orientado pela filosofia crítica, dizia Herculano, não restrito a Portugal, também já comum na Alemanha e na França. $O$ esforço do pesquisador deveria ser orientado por tais recursos, distanciando, gradativamente, o resultado de seu trabalho dos interesses de partido político e religiosos. Nesse horizonte, igualmente, a história passava a se pensar no coletivo. Não se tratava mais de julgar atos individuais, e sim de explorar a "índole das sociedades". Herculano acaba por constituir o movimento historiográfico de seu tempo pela Europa:

O uso dessas fontes, a aplicação dos preceitos a elas, tem produzido historiadores como Ranke, Guizot, Eichhorn, Savigny, Amári, e tantos outros que a Europa inteira conhece e admira. É a estes tipos que hoje forçosamente há de tentar aproximarse quem escreve história, se não quiser desonrar a literatura do seu país. Foi essa aproximação que eu tentei, persuadido de que bem merecia por isso da terra em que nasci (HERCULANO 1850 b, p. 6-8). 
Como se pode observar, o autor do opúsculo encaminha sua argumentação a partir da descrição de um conjunto de regras da pesquisa historiográfica que estaria, já àquele tempo, acordado entre alguns países da Europa. Ele condiciona, inclusive, a aceitação de seu ponto de vista acerca dos mitos religiosos de fundação de Portugal ao conhecimento das referidas regras e dos resultados obtidos a partir delas. $\mathrm{Na}$ sequência, Herculano diz não precisar da ciência no seu estado atual para dar suas explicações. Considerando que a polêmica que emergiu a partir da publicação da História de Portugal se tornou significativa o suficiente para ultrapassar os envolvidos e ocupar páginas de jornais durante um longo período, a relevância da divulgação do fazer historiográfico no ponto de vista de Herculano foi certamente significativa (SERRÃO 1977). Uma longa citação de Mabillion seguia a passagem supracitada, no intento de avançar nas definições que regem o trabalho com documentos históricos, sua crítica e a verdade que deles é possível extrair. $O$ impacto público da disputa entre a versão histórica de Herculano e a opinião do clero tem registro, por exemplo, na própria fala daquele:

eu disse que as autoridades, que estabeleceram as regras históricas aceitas por mim, serão irrecusáveis para aqueles mesmos que mais ferrenhos se mostram em conservar quanto os tempos passados nos transmitiram. Essas regras, pois, ao menos as principais, permita-me V. S. a que as transcreva aqui. Pasme Portugal de ver uma parte do clero insultar-me nos púlpitos e na imprensa, caluniar-me nas praças e corrilhos, porque segui como historiador as doutrinas estabelecidas, para se estudar e escrever a história da igreja, por homens que são a glória e a honra da classe sacerdotal. Se diante dos olhos de todos, na consciência de todos não estivesse quanto eu escrevi acerca da decadência intelectual da maioria do nosso clero, parece-me que o que vou transcrever seria medida sobeja para por ela se aferir essa verdade (HERCULANO 1850b, p. 9).

Na sequência, as citações do historiador religioso Fleury, autor da História eclesiástica, confirmam as impressões de Herculano acerca do lugar dos milagres na narrativa da história. Após o excerto transcrito, complementa Herculano: 
não peço a V. S. a tão cavalheiro e tão indulgente para comigo; peço ao homem que mais me odiar, mas que conserve um resto de pudor, que seja juiz entre mim e os desgraçados que não se envergonham, cristãos e sacerdotes, de invocar contra a História de Portugal tais princípios e tais máximas, e que insultam, não a mim, nem o meu livro, mas os apóstolos, mas a Bíblia, mas os escritores mais sábios, mais respeitados do catolicismo (HERCULANO 1850b, p. 15).

Herculano diz que escolheu dois homens "de incontestável ciência e catolicismo insuspeito", mas que poderia citar outros não menos autoridades (HERCULANO 1850b, p. 16-17). Concomitantemente, Cícero é quem ingressa no concurso de referências do historiador ao ataque do clero: "poderia invocar a bela sentença de Cícero: Quem ignora que a primeira lei da história é não ousar dizer a menor falsidade, e a segunda não nos faltar jamais valor para dizermos a verdade?". É certo que uma parte do clero português do século XIX se ergueria para responder-Ihe: - Ignoramo-lo nós" (HERCULANO 1850b, p. 17). O protestante João Lecrerc, com posição próxima à de Cícero no que tange à verdade da história, também seria citado, com o seguinte arremate: "não me quis aproveitar dessas autoridades sumas, porque um não era cristão, outro não era católico. Parece-me que é levar longe o escrúpulo" (HERCULANO 1850b, p. 17).

Como se pode observar na leitura do supracitado opúsculo, segue-se efetivamente uma longa doutrina em nome da verdade que pode ser considerada como propriamente histórica. Mais que apenas uma resposta ao clero português, Herculano fornece elementos à compreensão do estado da reflexão historiográfica em meados do Oitocentos em Portugal. A totalidade de textos que compõem a polêmica que foi brevemente aqui examinada, sem dúvida, estabelece oportunos recursos à leitura historiográfica, podendo, inclusive, ultrapassar o caso particular dos envolvidos na querela. Enfim, a segunda carta encerraria, por ora, a discussão: "cessou por isso nossa correspondência. Restam mil outros meios de falar com o geral dos homens de bem e sinceros, e de dizer ao meu país as verdades, em que a guerra da maioria do clero me obriga, por própria defesa, a fazê-lo pensar" (HERCULANO 1850b, p. 68). 


\section{REFERÊNCIAS BIBLIOGRÁFICAS}

BUESCU. Historiografia e mito: o caso de Alexandre Herculano. In: MATOS, Sérgio Campos; JOÃO, Maria Isabel (Org.). Historiografia e memórias (séculos XIX-XXI). Lisboa: Centro de História - Universidade de Lisboa; Centro de Estudos das Migrações e das Relações Interculturais Universidade Aberta, 2012, p. 126-142.

CARVALHO, Joaquim Barradas de. As ideias políticas e sociais de Alexandre Herculano. 2ed. Corrigida e aumentada. Lisboa: Seara Nova, 1971.

CATROGA, Fernando. Alexandre Herculano e o Historicismo Romântico. In: TORGAL, Luís Reis; MENDES, José Maria Amado; CATROGA, Fernando. História da história em Portugal. Lisboa: Temas e Debates, 1998, p. 84-87.

FOUCAULT, Michel. A ordem do discurso. Aula inaugural no Collège de France, pronunciada em 2 de dezembro de 1970. São Paulo: Edições Loyola, 2010.

HARTOG, François. Croire en I'histoire. Paris: Flammarion, 2013.

HERCULANO, Alexandre. Cartas sobre a história de Portugal. Revista Universal Lisbonense. Jornal dos interesses physicos, moraes, e litterarios. Por uma Sociedade Estudiosa. Lisboa: Imprensa Nacional, n. 27, p. 316-317; n. 29, p. 341343 ; n. 33, p. 395-396; n. 37, p. 437-439; n. 41, p. 485487 ; n. 44 , p. $516-518$; 1843 , n. 1 , p. $18-20$; p. 31 ; p. 4244; p. 55-56; p. 67-68; p. 75-78; p. 78-80, 1842.

HERCULANO, Alexandre. Cartas. Tomo I. Lisboa: Bertrand, s/d. HERCULANO, Alexandre. Cartas. Tomo II. Lisboa: Bertrand, s/d. HERCULANO, Alexandre. Considerações pacificas sobre o opúsculo Eu e o clero. Carta ao redactor do periodico - A Nação, 
por Alexandre Herculano. Lisboa: Imprensa Nacional, 1850a.

HERCULANO, Alexandre. Conversão dos godos ao catholicismo. In: Composições varias. Lisboa: Aillaud, Alves, Bastos e Cia Editores, s/d., p. 3-30.

HERCULANO, Alexandre. Historia de Portugal pelo Sr. A. Herculano (Carta do autor). Revista Universal Lisbonense, Tomo V. Lisboa: Imprensa da Gazeta dos Tribunaes, 1846, p. 509-513.

HERCULANO, Alexandre. Historia de Portugal. Tomo primeiro, Lisboa, em casa da viúva Bertrand e filhos, 1846.

HERCULANO, Alexandre. Imitação-Bello-Unidade. Repositório Literário da Sociedade das Sciencias Médicas e de Literatura do Porto, n. 7, p. 53-56; n. 8, p. 61$64 ;$ n. 9, p. 70-71; n. 11, p. 84-88, 1835.

HERCULANO, Alexandre. 0 clero portuguez. Lisboa: Typographia do Constitucional, 1841.

HERCULANO, Alexandre. Sôbre história e historiografia (Da "História de Portugal" e dos "Opúsculos"), por Alexandre Herculano (selecção, prefácio e notas de António Sérgio). Lisboa: Seara Nova, 1937.

HERCULANO, Alexandre. Solemnia verba. Cartas ao senhor A. L. Magessi Tavares sobre a questão actual entre a verdade e uma parte do clero por Alexandre Herculano. Lisboa: Imprensa Nacional, 1850b.

KNAUSS, Paulo. Uma história para o nosso tempo: historiografia como fato moral. História Unisinos, v. 12, n. 2, maio-agosto, p. 140-147, 2008.

MACHADO, Veronia Castanheira. "O dilatar da nação": a dimensão do político na historiografia de Alexandre Herculano (1839-1850). Dissertação (Mestrado em História) 
Universidade do Estado do Rio de Janeiro, Rio de Janeiro, 2011.

MARINHO, Maria de Fátima. O romance histórico em Portugal. Porto: Campo das Letras, 1999.

MATOS, Sérgio Campos. Narrativa e divulgação da história em Alexandre Herculano. In: Consciência histórica e nacionalismo, Portugal, séculos XIX e XX. Lisboa: Livros Horizonte, 2008, p. 159-170.

OLIVEIRA, Maria da Glória de. Fazer história, escrever a história: sobre as figurações do historiador no Brasil oitocentista. Revista Brasileira de História, São Paulo, v. 30, n. 59, p. 37-52, 2010.

PROENÇA, Maria Cândida. A regeneração. O conceito e a experiência nacional (1820-1823). Dissertação (Mestrado em História). Universidade Nova de Lisboa, Lisboa, 1987.

SARAIVA, Antonio José. Herculano e o liberalismo em Portugal: os problemas morais e culturais da instauração do regime. Lisboa: [s.n.], 1949.

SILVA, Taíse Tatiana Quadros da. Maquinações da razão discreta: operação historiográfica e experiência do tempo na Classe de Literatura Portuguesa da Academia Real das Ciências de Lisboa (1779-1814). Tese (Doutorado em História). Programa de Pós-Graduação em História, Universidade Federal do Rio de Janeiro, Rio de Janeiro, 2010.

SERRÃO, Joaquim Veríssimo. Herculano e a consciência do liberalismo português. Lisboa: Livraria Bertrand, 1977.

TURIN, Rodrigo. Uma nobre, difícil e útil empresa: o ethos do historiador oitocentista. História da Historiografia, Ouro Preto, n. 02, março, p. 12-28, 2009. 


\section{AGRADECIMENTOS E INFORMAÇŌES}

\section{Evandro Santos}

evansantos.hist@gmail.com

Professor de Teoria e Metodologia da História no Centro de Ensino

Superior do Seridó

Universidade Federal do Rio Grande do Norte

Rua Joaquim Gregório, s/n

59300-000, Caicó - Rio Grande do Norte

Brasil

Esta pesquisa contou com o financiamento da Coordenação de Aperfeiçoamento de Pessoal de Nível Superior (CAPES). 